\title{
Natural Protected Areas and Rural/Local Development: A Sustainable Strategy in Remote Areas
}

\author{
Marta Pallares-Blanch
}

Marta Pallares-Blanch, Department of Geography, Universitat Autònoma de Barcelona, Barcelona, Spain(marta.pallares@gmail.com)

\begin{abstract}
The value and resources of the landscape and heritage of the Pyrenees, conserved in Natural Conservation Areas, have not been included in local social/economic development. The necessary policies and transverse working methods have not taken on board the benefits of these natural, protected areas on local, economic development. In some parts of the Pyrenees like Alt Urgell county the process of naturbanisation is just beginning. There is a great opportunity to put the brakes on uncontrolled urban development. At the same time, the potential to exploit the heritage and resources of the Pyrenees still exists. Therefore, the research defences that Natural Reserved Areas can act as a driving force to articulate a quality label of landscape, heritage and territory in peripheral areas like West Catalan Pyrenees. At the same time, by through promotion of Natural Reserved Areas a multi-organisational project of local development can be build. In the framework of rural-urban dynamics in a global context, the paper explains how the values of landscape and heritage in the mountain areas can be an opportunity to put into practice integrated territorial policies applying transversal methodologies among actors, institutions and private sector. At the same time, local development projects would priories young people and women support as one of the sector more likely to innovate and to maintain social and human capital in peripheral areas. A cooperation and collaboration practices are needed to create new economic activities with the participation of local actors. This paper puts forward suggestions for action to be taken.
\end{abstract}

Keywords: natural protected areas, Pyrenees, local development, heritage, landscape

\section{Introduction}

This paper highlights the importance of Natural Protected Areas (NPA) in peripheral areas as a particular focal point for the benefits of sustainable rural/local development strategies. Research in this field aims to contribute to integrate conservationist and rural development discourses in the specific context of peripheral areas.

NPA traditionally have been managed by conservation principles, as the conservation and preservation of the natural heritage are their main objectives (Naughton-Treves 2005). However, NPA organizations in remote areas have to face other issues, in part due to the scarcity of local development strategies, which in turn are due, in part, to the limited human and economic resources of the local governments. In this context, NPA organizations have the potential for playing an important role in local development strategies.

The paper is structured in three main parts. The first part presents the fundamental concepts of urban-rural dynamics in Europe at present, with a focus on peripheral areas. The analytical framework applied is based on rural development theory, which has become an important issue in rural studies during recent decades, leading to the description of a new rurality that is growing in intensity throughout 
Europe territories. The second part presents the significance of NPA in the High Catalan Pyrenees, including the main results of empirical research on the role of NPA organizations at the local level that reveals their capacity to create sustainable rural strategies. Finally, a more decisive role for NPA policies, functions and values is encouraged in designing rural policies at the local level. In the same way, research on urban-rural dynamics would benefit from analysis of the effects of NPA to achieve a global comprehension of territorial, social and economic processes in rural natural areas.

\section{Urban-rural Restructuring Patterns and Spatial, Social and Economic Implications in Remote European Areas}

At the beginning of the 21 st century, agrarian activity in more advanced countries is, in many cases, insufficient even for subsistence, particularly in mountain and remote areas. The agricultural sector is no longer competitive in many areas and its function becomes more social than productive, particularly in areas with important biodiversity and natural and cultural heritage (Prados 2009).

Rural restructuring has received considerable research attention over the past two decades (Marsden et al. 2000; Bowler et al. 1996; Arkleton Trust 1987), with particular focus on diversification of the farm (McNally 2001), pluriactivity and parttime farming (Evans et al. 1993). Therefore, rural space is not exclusively agrarian just as agriculture is no longer an exclusively rural activity.

This restructuring process has produced different results throughout rural spaces as agrarian zones become concentrated and strongly specialized in very competitive production, while traditional agrarian land use is disappearing to leave room for residential, recreational or services uses (Dijst et al. 2005). Among the numerous aspects contributing to the intensification of the urban-rural dynamic, two emerge as the key factors: the general improvement of communication facilities, which goes hand-inhand with urban deconcentration, and increasing environmental awareness, which is associated with the growth of services and particularly tourism activity (Bowler 1992; Harper 1991). These two dimensions define the central structure of the rural system and reveal the impacts of the processes of change, which in turn are interrelated. Thereby, changes in land use, such as the transference of agricultural land into conservation/environmental protection zones, various impacts on the employment structure, and the resulting movements of population seeking either new employment or access to 'desirable' rural environments, all lead to new social structures in the countryside (Courtney et al 2006; Bowler 1992; Harper 1991).

Within these two dimensions, population movements to rural areas are the most widely studied. The emergence of new residential mobility patterns has been identified as one of the main consequences of the urban-rural dynamics during recent decades. The complex amalgam of factors intervening in movements, processes and residential options has been deeply analyzed, producing the concept of counterurbanization (Mitchell 2004). Recent literature explores the necessity of attending to urban-rural dynamics, including new factors emerging on the new rurality scene. This is the case of NPA attractiveness, which adds the pull factor of rural areas to the traditional vision of counterurbanization as a deconcentration process of urban areas (Prados 2009).

\section{Naturbanization: a new concept for new urban-rural dynamics}

In the context of urban-rural dynamics, the unique characteristics of the countryside have become economic 'commodities', for which an increasing demand has evolved (Marsden 2003, Cloke 2006, Elbersen 2005). This commodification has 
implied that rural areas gradually became integrated into urban society, representing important reserve space for the expanding activities in urban areas (Elbersen 2005).

Consequently, one of the effects of current urban-rural dynamics is the attractiveness of NPA as places not only to visit but to live nearby. The attraction to a segment of the population wishing to enjoy, work and live close to or within a Natural Park has recently been studied under the concept of naturbanization (Prados 2009). This new concept identifies, describes and analyses the existence of the processes of urbanization in relation to natural protected areas with specific natural values.

Naturbanization is a very specialized concept in the urban-rural dynamics theories that can be understood as a modality of the counterurbanization process (Prados 2005). Thus, naturbanization incorporates territorial frame as a reference for new processes, expressed in the renewal of traditional economic activities, in the emergence of new economic activities based upon heritage elements, and in population growth and land use changes in rural natural areas (Prados 2009). Hence, naturbanization incorporates into urban-rural dynamics theories the fact that rural areas have important natural and cultural heritage, often encapsulated in NPA designation (Prados 2009; Prados 2005; Jaillet 2004). Therefore, the inclusion of NPA effects in the urban-rural dynamic highlights NPA consequences for rural development strategies and for environmental preservation of rural natural areas (Prados 2009). In this sense, naturbanization refers to the 'métissage' character of the spaces instead of a confrontational approach (Jaillet 2004). Thus, NPA should not be seen as isolated areas, but rather as heritage reserves that can enhance local socioeconomic development, particularly in remote areas that may offer very limited job opportunities (NaughtonTreves 2005). However, the naturbanization process can have negative implications for ecological, landscape and social values if it is not predicted and regulated; that is why the process needs to be explored (Prados 2009).

\section{Naturbanization studies across Europe.}

The effects of the naturbanization process have been documented in several NPA across Europe, including the National Parks of Peneda-Geres in Portugal; Doñana, Sierra Nevada and Aigüestortes-and-Sant Maurici Lake in Spain; Ecrins in French Alps; the islands of Sardinia and Crete, and the National Park of Kampinoski in Poland (Prados 2009). The central focus of research to date on naturbanization is based on the affirmation that the creation and/or presence of protected natural qualities will have a positive influence on rural areas (Campagna 2009, Lourenço 2009, Prados 2005, and Tulla et al 2009). This is particularly the case of remote areas. In this sense, Prados (2009) showed significant impacts of naturbanization across NPA in Andalusia, whether they are located on the coast or inland, although the former received the most new residents attracted to the NPA. Despite lower population growth in these remote areas, population increased at higher rates than in rural municipalities without the NPA factor (Prados 2005). Thus, considering the weaknesses that remote areas present in terms of the lack of a critical mass, the potential of naturbanization offers an optimistic boost to demographic recovery and its implications for remote areas.

In the same direction, but with a different approach, other studies highlight the growing recognition of the important role played by natural heritage in rural economic development. An analysis of four case study areas in Scotland (Courtney et al 2006) found that rural areas with activities 'reliant' on natural heritage have the greatest potential for generating local economic benefits through their propensity to source locally. Thus, core activities (environmental maintenance, interpretation, tourism and consultancy) not only make a direct contribution to the local economies of the case 
study areas in terms of employment and expenditures, they also make a highly significant contribution to rural economies by underpinning those economic activities that are reliant on the actual or perceived quality of the natural heritage. Consequently, they play an increasingly important role in sustaining the viability of communities in rural Scotland (Courtney et al. 2006).

\section{Remote areas in Europe: only conservation areas?}

Peripheral areas of Europe such as remote and mountainous areas are quantitatively unimportant with respect to population. Nonetheless, they are significant because of the size of the area they cover and the recognition of the value of their landscape for both the indigenous population and outsiders (Brodda 2007; NaughtonTreves 2005).

Moreover, rural peripheries will continue as an important spatial category of European regional policy. The reasons are to be found not only with regard to the Cork Declaration $^{1}$ principles $^{2}$ but also taking into account the last CAP reform, which has moved from a production-oriented policy towards a more territorial approach to stir economic, social and environmental development in the countryside. In addition, it has to be considered that available land is becoming scarcer in densely populated Europe (Brodda 2007; Tulla et al. 2009).

However, striking regional disparities continue to exist or even increase between prospering and structurally weak areas. In this sense, rural programmes from the European Union have provided useful instruments to enhance local development in rural areas, and particularly the periphery, through the Leader Programme. As a result, some countries have supplemented their regional policy with a range of programmes rooted in the new paradigm of "endogenous regional development". The decentralization of regional policy and the explicit utilization of endogenous regional potentials are the key elements of these programmes. Unfortunately, they generally lack coordination and consistent funding, which is particularly required to sustain a minimum set of institutions that can assist the local or regional bottom-up processes (Brodda 2007). In this sense, from the regional development perspective and based on rural peripheral areas, Brodda's thesis (2007) explores the impact of strategies implemented under an integrated rural development frame, analyzing their relevance for the development perspectives of rural peripheries. Her findings give an idea about how the regional policy role of the nation-state is shifting from that of a distributor of welfare towards an "activating state" (Brodda 2007). As a consequence, new actors such as agencies and partnerships, but also voluntary networks and private institutions, are engaged in regional development and take over many formerly public tasks at the regional and local levels. The research shows that, in all three case studies examined, regional facilitators, regional development and instruments for capacity building have proven to be of crucial importance for (re)development (Brodda 2007). Nevertheless, in other countries prevalent social, demographic and territorial structures in peripheral areas might not always provide the conditions that would generate the new actors, organizations and methodologies needed in integrated rural and local development (Pallarès-Blanch 2009; Laguna 2007).

\footnotetext{
${ }^{1}$ EUROPEAN COMMISSION 1996

${ }^{2}$ The 10 points of Cork's Declaration can be summarised as the need to put sustainable rural development at the top of the agenda of the European Union and integrate the aim to preserve and improve the quality of the rural environment into all Community policies that relate to rural development.
} 


\section{Methodology}

In response to the High Catalan Pyrenees Regional Development Board, the Centre for Integrated Rural Development of Catalonia designed a study to evaluate the rural/local development potential of the region. The empirical qualitative research consisted of 42 semi-structured in-depth interviews with the main local development agents in the High Catalan Pyrenees area, including local authorities, tourist boards and heritage boards, rural development groups in the Leader Programme, agriculture schools, regional authorities and NPA organizations (both National and Natural Parks). Based on a review of literature (McAreavey 2009; Maya 2009; ODCE 2006; Marsden 2003; 2000; Douwe et. al 2000), the interviews addressed 9 fundamental strategies for rural/local sustainability. These strategies can be summarised as 1) Endogenous and exogenous development (acting as a territorial unit but cooperating with other territories), 2) Integrated development involving all economic sectors, 3) Projects articulated with other levels of administration, 4) Strategic plans, 5) Development projects in other fields (culture, environment, tourism, migration), 6) Participation of different actors, 7) Technical and political leadership, 8) Long-term perspective and 9) Desire for decentralization.

The study was structured in two main parts. First, the major challenges and unmet needs of the territory were evaluated. Then the strategies of organizations and actors dedicated to rural/local development were identified.

\section{High Catalan Pyrenees region: Between development and conservation}

The Pyrenees is a natural barrier $450 \mathrm{~km}$ long and $150 \mathrm{~km}$ wide, located along the border between Spain and France. Our case study is located in the High Catalan Pyrenees, one of the 7 administrative regions in Catalonia, the autonomous community of the northeast of Spain. Its $5,775.51 \mathrm{Km}^{2}$ constitute $18 \%$ of the entire area of Catalonia, while its 76,287 inhabitants are only $1 \%$ of the population, providing $1 \%$ of GNP (2008 Census $^{3}$ ). The region has the lowest population density of Catalonia, its 13 inhab. $/ \mathrm{km}^{2}$ contrasting with 230 inhab. $/ \mathrm{km}$ of Catalonia as a whole. Looking at these territorial indicators together with the long distances to main urban centres, the High Catalan Pyrenees can be considered a remote area with respect to the urban system of Catalonia and the overall Spanish urban system. The economy of the area changed from agrarian to tourism without first experiencing a true industrialization process. Distribution of the region's employed population across sectors is $9 \%$ in agriculture (2\% in Catalonia); $10 \%$ in industry (25\% in Catalonia); $17 \%$ in building $(10 \%$ in Catalonia) and $64 \%$ in services (62\% in Catalonia) $)^{4}$.

To have a better understanding of the weaknesses that this peripheral area generally presents, we must always keep in mind the aging of the population, which is related to the past emigration period of young people and has especially affected women (Pallares-Blanch 2009). In addition, the population loss due to emigration to cities has drained vital acquired knowledge and skills, making it more difficult to develop innovative production and organizational processes in both the public and private sectors. However, demographic rates started to present the first positive signs after several decades of decline thanks to new immigration flows since the late 90 s and particularly after 2000, mainly originating out of EU countries (Tulla et al 2009). This has been a general trend in rural areas: from 2001 to 2006 the population in Spanish rural municipalities tripled (Solé et al 2010).

\footnotetext{
${ }^{3}$ Catalan Statistical Institute www.idescat.cat

${ }^{4} 2001$ Available data for these figures, Catalan Statistical Institute www.idescat.cat
} 
In the High Catalan Pyrenees most immigration responds to employment demand in the services sector, basically related with tourism activities (accommodation, trade and restoration), personal services and, until recently, the construction sector. Other lesser flows also have to be considered: young people returning, neorurals developing activities which rely on natural and cultural values, organic agriculture and food quality production, and professionals seeking environmental quality. Although these minor flows are not quantified, they bring innovation and the general immigration flow has important consequences for the demographic structure, like the rejuvenation of the social fabric and increased active population; this is a key point in considering rural development capacity (Solé et al 2010).

\section{NPA in the High Catalan Pyrenees}

Powerful natural attractions of the High Catalan Pyrenees region can be found in its Natural Protected Areas. In this region we find the only National Park of Catalonia (Aigüestortes and Sant Maurici Lake), along with two other Natural Parks, High Pyrenees and Cadí-Moixeró. Therefore, $47 \%$ of the High Catalan Pyrenees is protected land, representing $29 \%$ of the protected land in Catalonia.

This natural heritage has favoured the increase in second residences and touristrelated services, primarily organised around ski resorts. Tourism and the related facilities both highlight and benefit from the landscape and cultural heritage values of the region (Pallares-Blanch 2009; Tulla et al 2009). The significance of second homes property in Spain has been considered in a comparative study of residential motivations close to NPA in England, Netherlands and Spain, the latter experiencing the greatest increase in second home ownership since 1945 (Elbersen 2005). The High Catalan Pyrenees region has the highest proportion of second homes in Catalonia, more than twice the number of primary residences (Tulla et al 2009). The distribution of second homes is uneven across the region, being more concentrated in the areas close to ski resorts, which are also where the most important NPA are located. In the same way, seasonal population in the region represents an additional $40 \%$ over total population ${ }^{5}$.

Apart from the second-homes ratio and seasonal population, there is still a lack of data to quantify the impact (area affected, evolution, quantity) of naturbanites and the degree of attraction exerted by natural values and more specifically NPA over residential mobility and job mobility. Nonetheless, it is clear that natural values and particularly NPA are highly influencing the model of development of the region.

Local development potentialities and the role of NPA in the High Catalan Pyrenees.

The main results from the research can be summarised at two levels. On the one hand, the prevalent dynamics related to the rural/local development capabilities of the region from the organizational perspective were defined. In this sense, the High Catalan Pyrenees, as a remote area, suffers from excessive distance to the pools of employment support. In addition, the geographical, historical, sociodemographical and political characteristics of the region do not facilitate the cooperation and commitment needed for a rural/local development strategy, and local authorities have neither the economic nor human resources to finance and create one. Consequently, there is a lack of

\footnotetext{
${ }^{5}$ The Instituto Nacional de Estadística (INE) (http://www.ine.es), which is the National Statistical Institute of Spain, included in the 2001 Census new questions to estimate the amount of seasonal population. The percentage has been calculated from original data on seasonal population in 2001 over total population in 2001. It is not probable that the percentage of seasonal population in 2010 would be higher. Although second homes continued increasing in the region after 2001 and almost until 2006, permanent population has also increased, from 64,067 inhabitants in 2001 to 76,828 in 2009 due to labour immigration flows basically (Solé et al, 2010).
} 
development strategy agreement among different sectors of society, which results in a segmented perspective (see Figure 1).

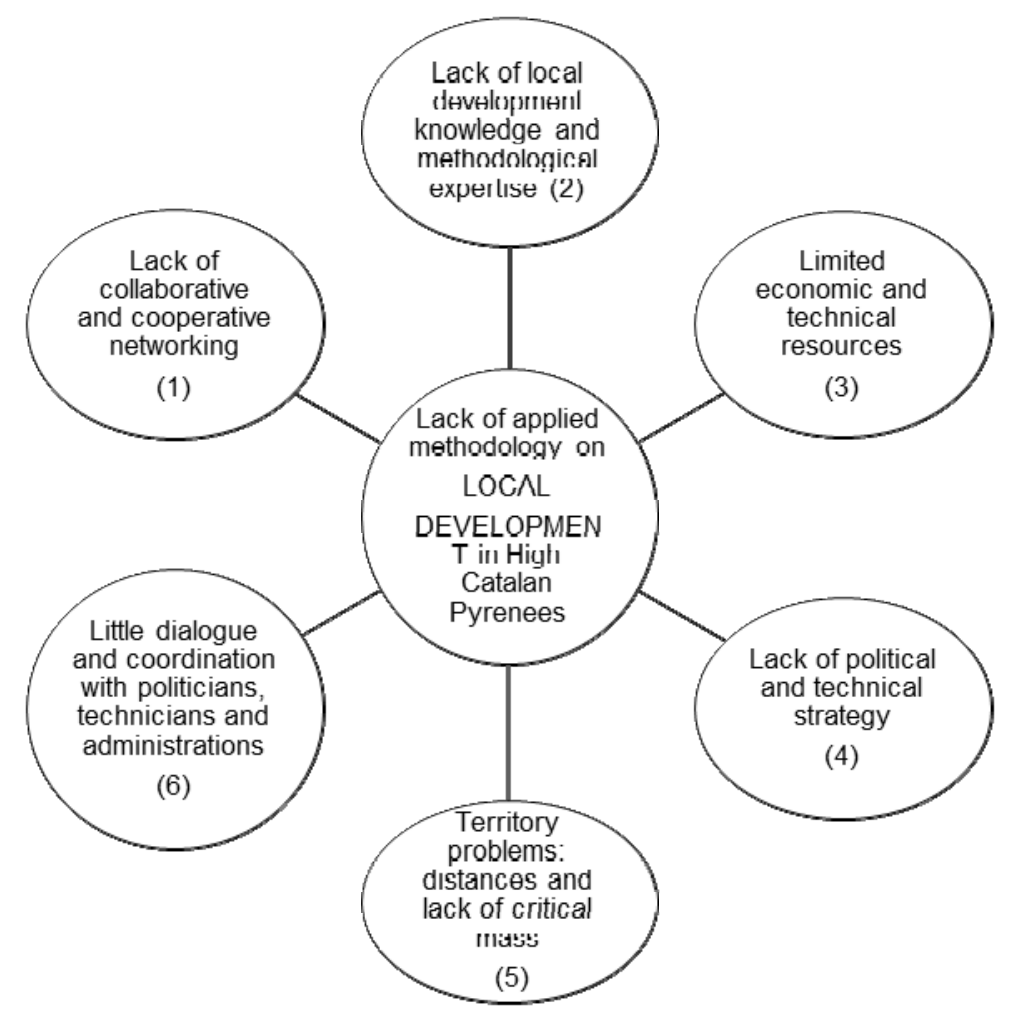

Figure 1: High Catalan Pyrenees and local/rural development strategy evaluated.

On the other hand and with specific regard to the benefits of NPA for rural development, the most relevant finding from our case study is that among all the organizations interviewed, NPA organizations presented the closer approach to a rural/local sustainable development methodology. This also seemed to be recognized by some of those interviewed. Indeed, NPA organizations and particularly the High Pyrenees Natural Park (a very recent and evolving structure and organisation), demonstrated a greater level of involvement and commitment with rural/local strategies. This can be assessed considering their participative methodology, cross-sectorial approach to programming, linkage with research and training programs, and the profile and skills of the technicians working there, who are mostly young people from urban areas.

Currently, NPA budgets in the High Pyrenees region are small, even though their approach is most likely to generate rural/local integrated development strategies in view of their capabilities to create co-operative networks, use transverse working methods and devote minimum technical structures to local planning. The tasks of sensitizing and encouraging participation of the local population and conversion of heritage into an economic resource require direction and consensus among the administrations with territorial responsibilities. Therefore, although the NPA in general, and High Catalan Pyrenees NPA in particular, cannot meet all of the more general needs of the region, they have the tools to encourage the local population, providing room for discussion on territory development models desired, actions to be taken, and how these are to be implemented. 


\section{Conclusions}

Naturbanization arises as a new concept that embraces the impact of urban-rural dynamics affecting NPA. These impacts can be positive or negative. The literature on naturbanization discusses the characteristics of the new dwellers' choices, creating new patterns of residential mobility in the areas and proving the attraction of NPA. Moreover, naturbanization seems to correspond to a common pattern around Europe and particularly in the most mature urban societies, which also have older NPA regulations.

In remote areas like the High Catalan Pyrenees, where a demographic and economic recovery has taken place basically due to the growth of tourist activities based on natural attributes, naturbanization offers an opportunity to build up sustainable strategies. Indeed, NPA organisations seem to drive rural/local development to the extent that several good practices have been applied more often and with significantly more impact than in other areas (Naughton-Treves 2005).

Remote areas like the Pyrenees have important natural resources and their NPA encapsulate them as the most important collection of natural and cultural values. Although the balance between conservation and development is a difficult issue under constant debate (Vaccaro 2005, 2009), activities relying on natural heritage promotion appear as the convergence of that potential in a sustainable way. Moreover, our research found NPA structures to be the organisations more likely to develop rural/local development strategies since they present some of the key factors required: community invigoration capacity, multi-organizational network involvement, long-term perspective and transverse working methods.

Remote areas also have many weaknesses that limit their capacity to create their own ways to develop rural/local development strategies. In this sense, it can be said that in remote areas like the High Catalan Pyrenees the flip side of having abundant natural and well-preserved resources is the lack of critical mass, as well as the absence of working teams to develop innovative projects. In this context, NPA organizations seem to arise as the driving force between development and conservation by attracting residents, and with them new direct and indirect employment and economic opportunities. Therefore, paying attention to the naturbanization process would highlight these opportunities at the same time that it would identify threats.

\section{Acknowledgments}

I would like to acknowledge the comments and suggestions made by Dr. Maria José Prados and Dr. Montserrat Pallares-Barbera and, particularly, Centre of Rural Integrated Development Foundation of Catalonia to entrust me with the coordination of the research. This work has been done within the framework of the UAB Ph.D. Program in Geography.

\section{References}

Arkleton Trust (1987), Farm Household Adjustment in Western Europe 1987-91. (Commission of the European Communities).

Brodda, Y. (2007), New Regional Development Concepts for Rural Peripheries Experiences from three European Case Studies: Western Isles and Skye \& Lochalsh, Scotland; Jämtland, Sweden and Eisenwurzen, Austria. (Thesis to be published in 2009 Göttingen, Germany).

Bowler, I.R., Bryant C.R. \& Nellis M.D. (1992), Contemporary Rural Systems in Transition. Vol. 2 Economy and Society. (Commonwealth Agricultural Bureaux International CABI. London: Redwood Press Ltd, Melksham). 
Campagna, M. (2009), 'Naturbanization processes in Sardinia 93-109', in M.J. Prados (eds), Naturbanization: New identities and processes for rural-natural areas (Taylor \& Francis Group, London).

Cloke, P. (2006), 'Conceptualizing rurality', in P. Cloke; T. Marsden \& P.H. Mooney (eds), Handbook of Rural Studies (London/Thousand Oaks/New Delhi).

Courtney, P.; Hill, G.; Roberts, D. (2006), 'The role of natural heritage in rural development: An analysis of economic linkages in Scotland', Journal of Rural Studies 22, 469-484.

Dijst M., Elbersen B., Willis K. (2005), 'The Challenge of Multi-functional Land Use in Rural Areas', Editorial Journal of Environmental Planning and Management, 48-1, 3- 6.

Douwe, J.; Renting, H; brunori, G.; Knickel, K.; Mannion, J., Marsden, T.; De Roest, K.; Sevilla-Guzman, E.; Ventura, F. (2000) 'Rural Development: From Practices and Policies towards Theory', Sociologia Ruralis, 40-4, $391-547$.

Elbersen, B. (2005) 'Combining Nature Conservation and Residential Development in the Netherlands, England and Spain' Journal of Environmental Planning and Management, 48:1, 37-63.

Evans, N. J. \& Ilbery, B. (1993), 'The pluriactivity, part-time farming and farm diversification debate'. Environment and Planning A, 25:7, 945-959.

Harper, S. (1991), 'People moving to the countryside: case studies of decision-making', in T. Champion \& Ch. Watkins (eds), People in the Countryside. Studies of Social Change in Rural Britain. (London: Paul Chapman Publishing Ltd).

Jaillet, M.C. (2004), 'Developpement et recomposition des espaces periurbains'. Conference Horizons Aquitans. La collection ressources. "Périurbain, périrural?" Lutte contre les discriminations, rénovation urbaine/pays touristiques Conference, 30 avril 2004, Pau.

Laguna, M. and Lasanta, T. (2007), 'Assessment of public policies related to rural development in the Aragonese Pyrenees' Boletín de la AGE 43, 365-368.

Lourenço, J.M., Quental, N. \& Barros, F. (2009), 'Naturbanization and sustainability at Peneda-Gerês National Park' 45-75. in: M.J. Prados (eds), Naturbanization: New identities and processes for rural-natural areas. (Taylor \& Francis Group, London).

Marsden, T. \& Bristow, G. (2000), 'Progressing Integrated Rural Development: A Framework for Assessing the Integrative Potential of Sectoral Policies', Regional Studies, 34:5, 455-469.

Marsden, T. (2003), 'The condition of rural sustainability: Issues in the governance of rural space in Europe', in: Kasimis, Charalambos \& Stathakis, George. (eds), The Reform of the CAP and Rural Development in Southern Europe (Aldershot).

Maya, A. \& Hidalgo, C. (2009), 'New Functions and Developments in European Rural Areas: The Need to Adapt to Long-Term Sustainable Production Methods', Boletín de la AGE 49 255-279.

McAreavey, R. (2009), Rural Development Theory and Practice. (Routledge)..

Mcnally, S. (2001), 'Farm diversification in England and Wales -What can we learn from the farm business survey?' Journal of Rural Studies, 17:2, 247-257.

Mitchell, C.J.A. (2004), 'Making sense of counterurbanization', Journal of Rural Studies 20, 15-34

Naughton-Treves, L.; Holland, M.; Brandon K. (2005), 'The Role of Protected Areas in Conserving Biodiversity and Sustaining Local Livelihoods' Annual Review of Environmental Resources, 30, 219-252 
Organization for Economic Cooperation and Develpment (2006), The New Rural Paradigm: Policies and Governance. (OECD Rural Policy Reviews).

Pallarès-Blanch, M. (2009), 'The benefits of Nature Reserve Areas in local development: An opportunity to develop a sustainable strategy in peripheral areas', in M.J. Prados, (eds), Naturbanization: New identities and processes for rural-natural areas. (Taylor \& Francis Group, London).

Prados, M.J. (2005), 'Territorial Recognition and Control of Changes in Dynamic Rural Areas: Analysis of the Naturbanization Process in Andalusia, Spain' Journal of Environmental Planning and Management 48:1, 65-83.

Prados, M.J. (2009), 'Conceptual and methodological framework of naturbanization' in M.J. Prados (eds) Naturbanization: New identities and processes for ruralnatural areas.(Taylor \& Francis Group, London).

Tulla A.F., Pallares-Barbera M. \& Vera A. (2009), 'Naturbanization and local development in the mountain areas of the Catalan Pyrenees' in M.J. Prados, (eds) Naturbanization: New identities and processes for rural-natural areas. (Taylor \& Francis Group, London).

Solé, A.; Solana, M.; Soriano, J.M; Tulla, A.F. (2010) 'La incidència de la immigració estrangera a l'Alt Pirineu i Aran'. Geography Department. Autonomous University of Barcelona and Department of Territorial Policy and Public Works of Catalonia Government.

Vaccaro, I.; Beltran, O. (2009), 'Livestock Versus "Wild Beasts": Contradictions In The Natural Patrimonialization of The Pyrenees', The Geographical Review 99:4, 499-516. 